\title{
WHAT (AND HOW) TO TEACH DESIGNERS ABOUT HUMANITARIAN INNOVATION?
}

\author{
John STEVENS \\ Royal College of Art, United Kingdom
}

\begin{abstract}
The Global Innovation Design (GID) master's programme aims to develop research and teaching collaboration opportunities between international academic institutions, and among a range of international Governmental and Non-Governmental Organisations. A theme of increasing interest is humanitarian innovation, in which many organisations are actively engaged. However, most academic documentation is in engineering and the humanities; there is little scholarly, empirical examination of design-led interdisciplinary methods and practice, spanning this fertile and important intersection, or of educational efforts to equip future designers with appropriate skills and knowledge. This paper outlines the developing educational context of experiential learning applied to innovation for disaster management and humanitarian response. Two examples of student design workshops on the subject of humanitarian or emergency response are described, to illustrate some of the benefits of immersive learning in this subject area (such as increased empathy and contextual understanding) weighed against the challenges (such as risk of physical or emotional harm) involved in first-hand encounter.
\end{abstract}

\section{Keywords: Humanitarian, disaster, design, innovation, experiential learning}

\section{INTRODUCTION}

\subsection{Educational context}

The past decade or so has seen a shift in expectation and understanding, that design can and should be a tool applied beyond the conception of desirable products in the service of commerce. A consequent growth in higher education provisions reflects a demand for design that addresses this shift, an increased appetite for design education that exposes students to learning opportunities to tackle the major global issues, through social innovations, policy design, and product-service system innovations. The GID master's programme was established to meet such a need, drawing largely on experiential learning [1] to develop technical skills, subject knowledge as well as cultural and contextual understanding. It adopts a multi-disciplinary, trans-national approach, bringing together students from various backgrounds and disciplines on a six-term (two year) course, including two terms overseas joining the masters curriculum at partner institutions (for more detail see [2,3]. Much of the programme follows widely-practiced studio teaching approaches, including focused class assignments, skill-building exercises, and self-set solo projects. However, the international element allows also for less prescribed but equally valuable experiential, immersive learning. Two examples of studio-based and immersive projects are shared in this account, both of them in the fields of design for emergency or humanitarian context. The first focuses on the designed outcomes from the workshop, the second on the experiential impact.

\subsection{Subject context - Innovation for Disaster Management and Humanitarian Response}

Although the subject of disaster research has moved into the mainstream of academic disciplines, the teaching about disaster management is somewhat marginalised, and most scholarly literature on teaching and learning in the context of disaster comes from medical and public health education programmes, and only now from social sciences and emergency management [4], some of which use immersive experiential learning (e.g. [5]). I suggest that innovation design education can valuably contribute to the discourse and can gain from adopting this approach. Since the publication of ALNAP's study on innovation in international humanitarian action in 2009 [6], the subject has risen in prominence, 
with a widespread expectation to bring much needed change in the humanitarian sector. ALNAP is a global network of NGOs, agencies, donors, academics and consultants dedicated to improving humanitarian response, and vocal advocates of increasing innovation practice in the sector (see also [7]). However, innovation theory is dominated by models from business and management, and largely sits "outside the adaption-development paradigm" [8], and some commentators challenge the direct translation of innovation principles from the commercial context, suggesting, for example, that the "fail fast' mantra of design-led innovation (see e.g. [9]) does not sit well with emergency contexts where lives are at stake. Arguably, such a view misses the point of the 'fail fast' ethos, which is precisely to mitigate and minimise risk by testing cheaply, safely and continuously during the new product development process. However, recent discourse suggests that expectations of humanitarian innovation are set at a higher level than new product development, and that it might provide "... a vehicle for institutional, cultural, and social change... as a transformative, ideational realisation of the humanitarian imperative ... or more modestly as a technical fix that could improve aspects of aid and aid provision" [6]. While such high ambitions resonate with the ethos of the master's programme outlined above, this question is beyond the scope of this article; the following project examples fall in this 'more modest' category of technical fixes which, while not likely to transform or disrupt the humanitarian landscape, may result in genuine impact.

The following sections outline and compare two project examples that have been major or contributory elements of the master's curriculum in innovation design. Both include an intensive 'design sprint' format (loosely following a structure based on Google Ventures' Design Sprint [10]). Example 1 was conducted in the comfort of the college studios, the participants having no direct contextual experience, whereas example 2 was part of a 'cultural immersion' project, through which the participating students had a significantly greater contextual experience.

\section{PROJECT EXAMPLE 1 - DESIGN SPRINT WORKSHOP}

This two-day workshop was undertaken in London to explore design possibilities for an innovative textile, to provide the developer Real Relief (a for-profit manufacturer in Denmark [11]) with a range of creative ideas that might be further refined and developed, to improve the application of their SuperTowel technology for hand cleansing, in a humanitarian context. The workshop was conducted with nine master's students from the School of Design over two days, in February 2018. The event was led and facilitated by the author and textiles tutor Vicki Fong, and also attended by Torben Holm Larsen, Technical Director, Real Relief, and Sian White, Research Fellow at London School of Hygiene and Tropical Medicine. The SuperTowel is a microfibre towel treated with a permanent anti-microbial bonding, designed as a soap alternative in emergency situations, when handwashing is critical for disease control, but it is also inconvenient and difficult to practice. The product has a dual mode of action: rubbing the skin with the fabric provides mechanical removal of bacteria and dirt from hands, and the antimicrobial treatment disinfects the towel [11].

\subsection{Workshop Structure}

\subsubsection{Day One}

1. Briefing: an overview of the workshop purpose and structure was given by the facilitators.

2. Technical and contextual background: chemical and microbiological principles behind Super Towel (Holm Larsen); key issues and challenges in humanitarian Water, Sanitation and Hygiene (WaSH) (White)

3. Context discussion: the whole group discussed the details of the brief, identifying three key challenge themes, based on prior lab research and field trials of the product: (1) use form and texture to improve abrasion and tactile feedback? (2) communicate "always with me, always wet"? (3) use form and decoration to communicate, "for hands only, use with water"?

4. Facilitated Idea Generation: Participants were divided into three groups, each assigned one of the three challenge themes. Individuals conducted semi-structured rapid ideation then shared ideas within their group, then to the whole assembly.

5. Groups discussed and sorted ideas into themes and directions of promise, incorporating feedback from expert advisors. 


\subsubsection{Day Two}

1. Groups explored selected ideas through making rough sketch models with a wide variety of fabric samples and other materials. Sewing machines as well as simple craft tools were readily to hand; water and dirt samples were available to test functional and tactile qualities (Figure 1).

2. Advice and feedback were given from subject experts during the sketch modelling session.

3. Final concept round-up and close.

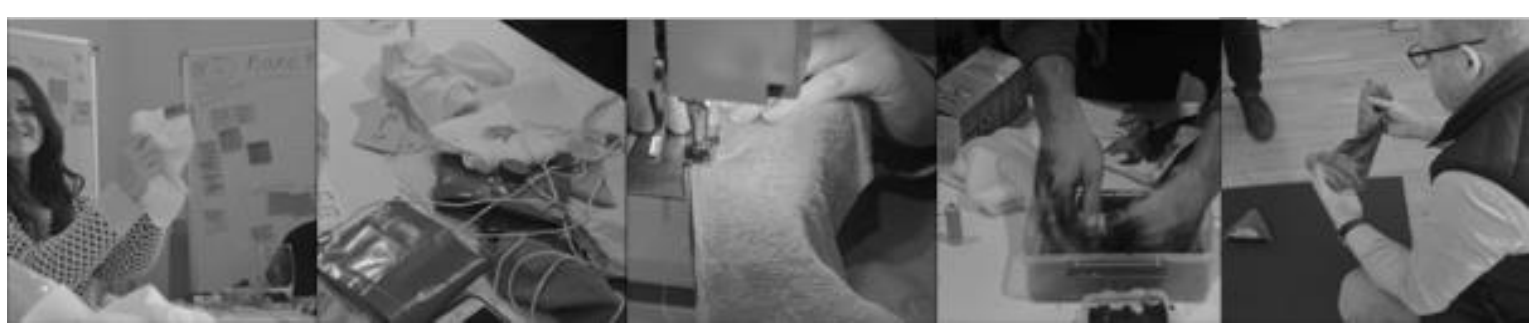

Figure 1. Workshop activities

\subsection{Design Outcomes}

The key outcome from the workshop was a range of proposals in tangible forms - several dozen models (examples in Figure 2) that the project sponsor was able to take away to consider and share with colleagues. In his words, the workshop was "a tremendous eye-opening experience and a great value to the further development of the project".

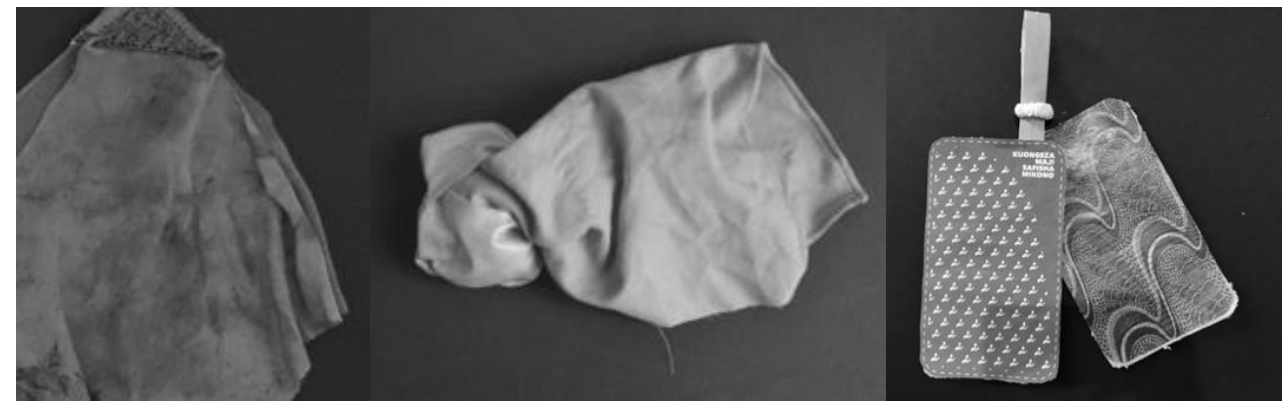

Figure 2. Example sketch models exploring (from left); secondary structure dirt removal properties; tertiary structure folding into pocket or pouch; graphic treatment signalling use and local cultural references

As a direct consequence of the workshop, the prototypes used in subsequent lab and field trials were revised, increasing the functional efficacy of the towel (better dirt removal), and also incorporating a carry pouch which demonstrably increased the likelihood of use. Lab tests found that three of the four SuperTowel prototypes derived from this workshop were more efficacious at removing E.coli from precontaminated hands than handwashing with soap [12]. Another advantage reported is that the SuperTowel uses less water than handwashing with soap.

\section{PROJECT EXAMPLE 2 - IMMERSION INCLUDING DESIGN SPRINT}

During a typhoon in July 2017, the north of the Kyushu prefecture, in Southwest Japan, suffered extreme heavy rainfall, causing flooding and landslides, bringing scores of fatalities, as well as destruction of infrastructure, homes and livelihoods. One year on, we visited the region for a six-day field study and workshop exploring the challenges and innovation opportunities in natural disaster preparedness and recovery. Ironically the impact on participants of this immersive experience was greatly increased due to a similar but more damaging weather event occurring during our visit. in July 2018, a typhoon brought 'historic' levels of torrential rain to western Japan, this time wreaking even more damage to Kyushu and devastating areas in nearby Hiroshima. 5 million people were advised to evacuate their homes, and tens of thousands of rescue workers were mobilised. Tragically, over 200 people lost their lives [13].

\subsection{Project Structure}

At Kyushu University the group conducted a problem space mapping exercise, in which they discussed recorded and clustered a range of key themes and concerns. This included contributions from 
Environmental Risk Management specialist, Associate Prof Michal Hall, and from our host and coordinator, Assistant Prof Tokushu Inamura.

Exploring Kyushu city, students met local residents, farmers and business owners who shared their experiences of the past year. E.g. farmers found viable crops to grow in the paddies ruined by the floods and landslides. These shallot-like onions were being sold with pride at a public evert celebrating the farmers' resilience and resourcefulness.

Michihito Satogawa explained how he raised funds and awareness of the landslides in Asakura, in which many parts of the region had been struck by floods of mud and timber, washed from the hillsides above. He created log lanterns from the sawn, dried lumber and branded them with the Asakura name - many were sold online and shipped all over Japan.

Another local entrepreneur Daigoro Yamada shared his plans to rebuild and restore an abandoned, flooddamaged building for his bicycle ecotourism business which he hopes will bring valuable tourism to revitalise the area.

Asakura disaster volunteers Hotarubi (ホタルビ) showed us a site hit by the deluge and shared details of the challenges of mobilising volunteers, rescuing vulnerable civilians, and coordinating resources such as donations and equipment.

At Asakura Shiritsu Haki Elementary School, the group was honoured to join the presentation ceremony for a sculpture donated to the school by artist Tomotari Mikako: a large dragon carved from timber washed down the hillside during the landslides. The dragon is said to represent the power of water, for good and bad, and the artist gave a moving explanation of her work to the children, many of whom were affected by the events of 2017, having lost family members or their homes.

Most poignantly, we were welcomed to a commemorative ceremony held at the temporary housing for people displaced by the floods and landslides. This multi-faith event allowed for spiritual reflection and community gathering. Food and drinks were shared, bamboo lanterns shone with messages of hope and remembrance, and Buddhist, Shinto and Christian prayers were said before all were invited to light incense and make their own contemplation.

After this full and emotionally challenging schedule, a sprint innovation workshop was held in Kyushu University's outdoor education centre, in the hills east of the prefecture. By this time the typhoon had grown in severity, emergency measures were in place, and the area was on high alert for landslides and flooding once again. Working in five teams, the students produced a variety of promising concepts, despite the sprint session ending one day early to allow for safe return to the city and onward transit.

\subsection{Project Outcomes}

A range of innovative design proposals arose from the workshop, although a planned prototyping session was not possible due to the weather events. Concept themes ranged from preparedness (through education, training and resource co-ordination), to emotional resilience and recovery (community engagement and public art). Students demonstrated learning in the subject of humanitarian challenges, design-led innovation methods (including observational and participatory research), as well as benefitting from the cultural exchange between Japanese and international master's students. All participants gained mutually from the diversity of skills, knowledge and cultures involved, and especially from the direct experience of being in an area on high alert.

\subsubsection{Student Feedback}

"It was an invaluable opportunity to connect with a diverse group of people... from school children to rescue volunteers [which] gave me a glimpse into key aspects of life in rural Japan... All told, I took away a uniquely personal understanding of the challenges that help frame the human element of managing risks of extreme weather conditions more broadly." - Alison

"An invaluable collaboration with the University of Kyushu's experts and students, as well as local citizens and authorities, who helped us unfold the complexity of living with and recovering from a natural disaster. Their understanding of the problem, combined with our creative system-level thinking, fed the creation of great outcomes, in my opinion." - Chiara

"The most valuable takeaway for me was the opportunity to do first hand user research in a specific context we otherwise would not have been able to access. Bilingual communication and the cultural empathy required was a new and fascinating experience for me during my time in Japan and will hopefully be something I continue to do." - Fernanda 
"[In Tokyo I could not experience] seeing rural human ecosystems, and seeing the area's infrastructure (buildings, roads, safety protocols) first hand during a typhoon". - Dipali

\section{CONCLUSIONS}

The two examples illustrate contrasting possibilities of experiential teaching design for disasters. Example 1, conducted far from the use context, led to valuable outcomes as confirmed by the project sponsor, and students reflected positively on the learning experience. However, all contextual understanding was second hand and indirect, heavily reliant on participants' empathic ability as designers, and limited to the what the expert contributors considered relevant - despite their capabilities to provide relevant and comprehensive background information, there was little likelihood of serendipitous insights.

In contrast, example 2 was a far bigger undertaking, in planning and coordination as well as travel and duration. Students were able to practice direct observation through encounter, an invaluable skill in design research which can elicit insights that might never be made otherwise. The design outcomes show potential but remain undeveloped, yet still the example demonstrates how the direct experience of context and of personal contact with people affected have a clear and lasting learning impact on participants. This comes with a risk which must be carefully weighed. The experience of leading students to a typhoon-hit region was sobering, and although all remained calm and professional throughout, it was clearly challenging at times, and educators must consider the ethics of exposing students to emotional distress or fear, as well as to the real physical risks. As we consider research visits to refugee camps or to communities hit by natural disasters, there is little doubt such experiences would be immensely valuable and rewarding for certain students. I suggest that the field of humanitarian innovation is worthy of teaching approaches separate and distinct from commercial product design, and would benefit whenever possible from experiential, immersive projects. If successful, these approaches may help in the education of designers who are able to produce effective innovations with have real impact in emergencies.

\section{AKNOWLEDGMENTS}

Thanks to Torben Holm Larsen (RealRelief) and Sian White (LSHTM) for their expert insight and guidance, and for inviting our involvement in their valuable work; RCA Textiles tutor Vicki Fong, MA students C Ducret, M Grasso, Y Makhdoomi, D Landin Burbano, P Corker-Marin, M Andrea, A Davies, I Ohlson and F Dopal for their hard work and enthusiasm, and the resulting innovations. Thanks also to the Daiwa Foundation whose generous grant enabled RCA students to travel from Tokyo to Kyushu; MA students F Regalia, K Heikkinen, L Fossi, L Meskanen-Kundu, S Kawano, F Dobal, C Treglia, P Richard, D Aphale, D Alami, and A O'Reilly, for their hard work and good humour through a physically and emotionally challenging week; our hosts at Kyushu University, especially Inamura 'Tocky' Tokushu, ever-smiling leader and interpreter, for a unique and rewarding experience and for keeping us safe; the kind people of Asakura, Kyushu, who shared so openly their difficult experiences and reflections, especially staff and students of Shiritsu Haki Primary School, Tomotari Mikako, Daigoro Yamada and Michihito Satogawa.

\section{REFERENCES}

[1] Kolb D.A. Experiential learning: Experience as the source of learning and development, 2014

[2] Stevens J. and Townsend H. Building cross-border communities: trans-national innovation design students create trans-cultural innovations and a global network of practice. DS 88: Proceedings of the 19th International Conference on Engineering and Product Design Education (E\&PDE17), Building Community: Design Education for a Sustainable Future, Oslo, Norway, 7 \& 8 September 2017. 2017

[3] Stevens J.S., Mueller-Russo K., Fujikawa M., Childs P.R.N., Pennington M., Diskin S., et al. Design Without Borders: A Multi-Everything Masters. 3rd International Conference for Design Education Researchers. 2015;3: 1255-1266.

[4] Haney T.J. and Lovekamp W.E. On the Margins, No More: Teaching and Learning as a Core Concern of Disaster Scholarship - Introduction to the IJMED Special Issues on Teaching and Learning. International Journal of Mass Emergencies and Disasters. 2018

[5] Browne K.E. and Even T. The 'Culture of Disaster' Student Immersion Project: First-Hand Research to Learn about Disaster Recovery after a Colorado Flood. International Journal of 
Mass Emergencies \& Disasters. 2018;36: 264-286.

[6] Sandvik K.B. Now is the time to deliver: looking for humanitarian innovation's theory of change. Journal of International Humanitarian Action. 2017;2: 8.

[7] ALNAP More than just luck: Innovation in humanitarian action. Available: https://www.alnap.org/help-library/more-than-just-luck-innovation-in-humanitarian-action [Accessed on 2019, 8 Mar], (2016).

[8] Hope M., McCloskey J., Hunt D., Crowley D. and NicBhloscaidh M. Innovation Pathways to Adaption for Humanitarian and Development Goals: A Case Study of Aftershock Forecasting for Disaster Risk Management. Journal of Extreme Events. 2018;05: 1850010.

[9] Martin R.L. Design of Business: Why Design Thinking is the Next Competitive Advantage, 2009 (Harvard Business School Press, Cambridge, Mass).

[10] Knapp J., Zeratsky J. and Kowitz B. Sprint: How to solve big problems and test new ideas in just five days, 2016 (Simon and Schuster,

[11] RealRelief SuperTowel. Available: http://www.realreliefway.com/en-us/life-savingproducts/health/supertowel\%E2\%84\%A2/supertowel\%E2\%84\%A2 [Accessed on 2019, 8 Mar], (2018).

[12] Holm Larsen T. and White S. American Journal of Hygiene and Tropical Medicine. 2019; In press.

[13] Demetriou D. Japan floods: Fears of disease outbreaks as death toll tops 200. Available: https://www.telegraph.co.uk/news/2018/07/13/japan-floods-fears-disease-outbreaks-death-tolltops-200/ [Accessed on 2019, 10 March], (2018). 